\title{
Surgeon burnout: It is time to make solutions a priority
}

\author{
Alp Sener, MD, PhD
}

Department of Surgery, Division of Urology, Schulich School of Medicine \& Dentistry, Western University, London, ON, Canada; Department of Microbiology and Immunology, Schulich School of Medicine and Dentistry, Western University, London, ON, Canada

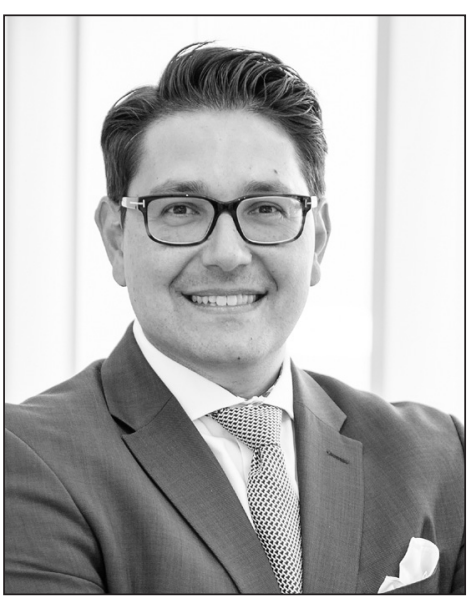
with a five-fold increase in the number of peer-reviewed articles published evaluating it compared to the last decade. It impacts us all either directly or indirectly and, as many authors would argue, up to $45 \%$ of people reading this supplement would test positive for burnout - a staggering number! As surgeons, we are consistently subjected to high levels of stress in our day-to-day work and often face uncertainties in our practice. We are exposed to extremes of emotions as we care for our patients, ranging from solitude, sense of failure, and frustration when the patient's illness progresses, feelings of powerlessness against illness and associated losses, and absolute success on the other end of the spectrum. Many reports have highlighted our inherent risk for experiencing mental disorders, substance abuse, suicide, and impairment in functioning. ${ }^{2}$ Despite this, we are also statistically the least likely group to openly discuss these feelings. Could it be because we somehow feel that our feelings and vulnerability may betray our code as "surgeons"? Hopefully, that type of false magical thinking no longer prevails in 2021.

None of us are immune. Physicians experiencing burnout are at higher risk of making poor decisions, displaying hostile attitudes toward patients, making medical errors, having difficult relationships with coworkers, and experiencing ailments such as major depression, anxiety, sleep disturbance, and substance abuse. ${ }^{3}$ Often, these lead to marital problems, early retirement, and sadly, sometimes suicide. The impact is therefore not only personal but also affect the remaining $60-70 \%$ of the group by leading to loss and significant workload and work force gaps.

Much of the data evaluating physician burnout comes from several key population-based and survey-based studies. The seminal publication came in 2011 from Mayo clinic, with a followup re-evaluation in $2014 .{ }^{4}$ They showed an approximate $10 \%$ increase in overall burnout rates among U.S. physicians compared to the general population. A closer look revealed that urologists demonstrated some of the highest rates of burnout, leading the pack in the top-tertile of all physicians and surgeons in the U.S. in both surveys. A followup survey by Medscape in 2019 unfortunately put urologists at the top of the pack again with respect to burnout among all physician groups in the U.S., with a rate of $54 \%$ compared to the average across all specialties of $44 \%$. The American Urological Association took these findings very seriously and showed, through a directed survey to all its constituents, that burnout rates were closer to $40 \%$, and not nearly as high as previously reported. Although this important revelation was somewhat reassuring that as urologists, we were not the most burned out among our surgical compatriots, it still left us with many questions and food for thought that we needed to do better. Having over 
a third of our colleagues suffering the deleterious impact of burnout is still motivation enough for us all to want to devise an improved system.

Then what is the best solution? Is there a cut-and-paste formula or a recipe book to follow to minimize burnout? Sadly, there is no magic bullet. The key step from various sources suggests that self-awareness followed by openness to assistance and solutions as the hallmarks to begin healing and minimizing the deleterious and snowball effects of physician burnout. Although there is no one-size-fits-all solution for everyone impacted by burnout, studies suggest that a dedicated, collective, and concerted effort by not only the impacted individual but also by the institution where one works has the most beneficial and impactful outcome towards improving wellness for physicians. ${ }^{5}$

This special edition of the Canadian Urological Association Journal will cover some very topical themes around physician burnout, ranging from exploring our own Canadian Urological Association census data in comparison to our U.S. counterparts to other articles evaluating the impact of COVID-19 and residency training on burnout. We will get perspectives on burnout from our European colleagues, as well as a dive into the controversial topic of physician hierarchy and its potential influence on burnout among urologists. Several authors will independently explore the concept of the second victim syndrome and the importance of peer support networks in mitigating moral injury, crisis management, and burnout across surgical subspecialties. Lastly, we received several powerful personal narratives from colleagues who felt comfortable sharing their personal challenges and experiences with burnout; these stories reflect what many of us have felt or experienced over the years, and we thank them deeply for their bravery and honesty.

Taking a proactive step towards minimizing burnout among our colleagues is a responsibility we all should carry. Educating hospital and departmental leadership that burnout is real forms the landmark step for top-down changes and programs. Making wellness a quality indicator for our hospitals and practice groups is a good start. Appointing a Chief Wellness Officer can provide legitimacy and financial support to wellness efforts. Distributing annual wellness surveys and collectively discussing the results regularly with leaders and employees will allow us to evaluate wellness initiatives prospectively to ensure they are meaningful and satisfactory. Creating a sustainable culture of wellness and resiliency through a peer-topeer support program will empower faculty and trainees to confront burnout more readily.
Personally, I have been interested in this topic for the better part of a decade. I have witnessed colleagues, mentors, residents, and students each work through various degrees of burnout and wondered why some people were more likely to experience it while others appear to be spared. Through these observations, I have come to realize that although we may not be able to shield our "susceptibility" to burnout, we may be able to alter our approach to at least minimizing its impact on us - I call it the GATOR approach to burnout (Table 1). Just as a gator seems impervious to most of the things surrounding it, taking these simple steps may help us provide a solid defense and build resiliency against external pressures contributing to our burnout.

In reading through this supplement, think of how you can contribute to the wellness of another colleague. Our behavior and grass roots efforts are extremely important in fostering an environment of openness, honesty, courage, and kindness in the teaching and practice of urology. Urologists have pioneered many surgical firsts that have had tremendous impacts on the care of millions of patients globally. Perhaps it is now time to turn some of that attention inwards - we should use our ingenuity, empathy, drive, and collaborative nature to spearhead local, national, and international efforts in helping the $40 \%$ of us who are burdened by burnout and ensure that physician wellness is a priority at our institutions and associations. These efforts will surely be contagious across other surgical specialties.

\begin{tabular}{|c|c|c|}
\hline $\mathrm{G}$ & GOALS & $\begin{array}{l}\text { Set career goals that are realistic, specific, } \\
\text { challenging, and fun }\end{array}$ \\
\hline A & $\underline{A D O P T}$ & $\begin{array}{l}\text { Adopt a healthy work and life balance; and } \\
\text { LOVE what you do! }\end{array}$ \\
\hline $\mathrm{T}$ & IEAM & $\begin{array}{l}\text { Create an honest support team/network, } \\
\text { nurture relationships (at home and at work), } \\
\text { and express gratitude to those around you }\end{array}$ \\
\hline $\mathrm{O}$ & OWNERSHIP & $\begin{array}{l}\text { Take charge of your own happiness: } \\
\text { - Become self-aware of what truly makes } \\
\text { you content, anxious, and frustrated } \\
\text { - Participate in relaxing activities } \\
\text { (vacations, hobbies, exercise) } \\
\text { - Practice mindfulness and find meaning } \\
\text { outside of work }\end{array}$ \\
\hline $\mathrm{R}$ & REACH OUT & $\begin{array}{l}\text { Reach out to someone if you think you are on } \\
\text { your way to being burnt out }\end{array}$ \\
\hline
\end{tabular}




\section{References}

1. Richelson, H. F. (1980). Burnout: The High Cost of High Achievement: Doubleday.

2. Oskrochi Y, Maruthappu M, Henriksson M, et al. Beyond the body: A systematic review of the nonphysical effects of a surgical career. Surgery 2016;159:650-64. htrps://doi.org/10.1016/i. surg.2015.08.017

3. Franc-Guimond J, McNeil B, Schlossberg SM, et al. Urologist burnout: Frequency, causes, and potential solutions to an unspoken entity. Can Urol Assoc J 2018;12:137-42. https://doi.org/10.5489/ cuaj.4668
4. Shanafelt TD, Hasan 0 , Dyrbye LN, et al. Changes in burnout and satisfaction with work-life balance in physicians and the ceneral U.S. working population between 2011 and 2014. Mayo Clin Proc 2015;90:1600-13. hittps://doi.org/10.1016/i.mayocp.2015.08.023

5. Panagioti $M$, Panagopoulou E, Bower $P$, et al. Controlled interventions to reduce burnout in physicians: $A$ systematic review and meta analysis. JAMA Int Med 2017;177:195-205. https://doi.org/10.1001/ jamainternmed.2016.7674

Correspondence: Dr. Alp Sener, Department of Surgery, Division of Urology, Schulich School of Medicine \& Dentistry, Western University, London, 0N, Canada; Alp.sener@lhsc.on.ca 